\title{
New Lesion Progression
}

National Cancer Institute

\section{Source}

National Cancer Institute. New Lesion Progression. NCI Thesaurus. Code C103420.

An assessment of the equivocality of disease progression based on a newly identified lesion. 